SPRINGER BRIEFS IN

APPLIED SCIENCES AND TECHNOLOGY

Zahra Trad

Abdelwahed Barkaoui

Moez Chafra

João Manuel R. S. Tavares

\section{FEM Analysis of} the Human Knee Joint A Review

Springer

1st ed. 2018, XVII, 79 p. 39 illus. in color.

\section{Printed book}

Softcover

$59,99 €|£ 49.99| \$ 69.99$

${ }^{[1]} 64,19 €(D)|65,99 €(A)| C H F$

66,00

eBook

$51,16 €|£ 39.99| \$ 54.99$

[2] $51,16 €(D)|51,16 €(A)| C H F$

52,50

Available from your library or

springer.com/shop

MyCopy [3]

Printed eBook for just

€ | \$24.99

springer.com/mycopy
Z. Trad, A. Barkaoui, M. Chafra, J.M.R.S. Tavares

\section{FEM Analysis of the Human Knee Joint}

\section{A Review}

Series: SpringerBriefs in Applied Sciences and Technology

- Presents the state of the art in a rapidly developing field

- Reviews FEM analysis of the human knee joint and HTO knee surgery

- Gives an overview of clinical and biomechanical studies

In recent years, numerous scientific investigations have studied the anatomical, biomechanical and functional role of structures involved in the human knee joint. The Finite Element Method (FEM) has been seen as an interesting tool to study and simulate biosystems. It has been extensively used to analyse the knee joint and various types of knee diseases and rehabilitation procedures such as the High Tibial Osteotomy (HTO). This work presents a review on FEM analysis of the human knee joint and HTO knee surgery, and discusses how adequate this computational tool is for this type of biomedical applications. Hence, various studies addressing the knee joint based on Finite Element Analysis (FEA) are reviewed, and an overview of clinical and biomechanical studies on the optimization of the correction angle of the postoperative knee surgery is provided. 